\title{
Effects of Vegetation on Urban Heat Island Using Landsat 8 OLI/TIRS Imagery in Tropical Urban Climate
}

\author{
Sri Sutarni Arifin ${ }^{1,2, *}$, Baharuddin Hamzah ${ }^{1, *}$, Rosady Mulyadi', Abd. Rachman Rasyid ${ }^{3}$ \\ ${ }^{1}$ Department of Architecture, Faculty of Engineering, Hasanuddin University, South Sulawesi, Indonesia \\ ${ }^{2}$ Department of Architecture, Faculty of Engineering, Gorontalo State University, Gorontalo, Indonesia \\ ${ }^{3}$ Department of Urban and Regional Planning, Faculty of Engineering, Hasanuddin University, South Sulawesi, Indonesia
}

Received September 17, 2021; Revised December 17, 2021; Accepted January 16, 2022

\section{Cite This Paper in the following Citation Styles}

(a): [1] Sri Sutarni Arifin, Baharuddin Hamzah, Rosady Mulyadi, Abd. Rachman Rasyid, "Effects of Vegetation on Urban Heat Island Using Landsat 8 OLI/TIRS Imagery in Tropical Urban Climate," Civil Engineering and Architecture, Vol. 10, No. 1, pp. 395-405, 2022. DOI: 10.13189/cea.2022.100134.

(b): Sri Sutarni Arifin, Baharuddin Hamzah, Rosady Mulyadi, Abd. Rachman Rasyid (2022). Effects of Vegetation on Urban Heat Island Using Landsat 8 OLI/TIRS Imagery in Tropical Urban Climate. Civil Engineering and Architecture, 10(1), 395-405. DOI: 10.13189/cea.2022.100134.

Copyright $\mathrm{C} 2022$ by authors, all rights reserved. Authors agree that this article remains permanently open access under the terms of the Creative Commons Attribution License 4.0 International License

\begin{abstract}
The decrease in the number of vegetated areas has an impact on increasing Land Surface Temperature (LST) which encourages the formation of urban heat islands. A lot of literature discusses the correlation between soil surface temperature and vegetation, but does not consider the geographical aspects and climatological conditions of the tropics located at the equator. Therefore, this study aims to analyze the effect of vegetation cover and surface temperature in the research area which will later be used as a reference in recommending the need for green open spaces in urban areas with tropical climates. In this study, a case study was conducted in the city of Gorontalo using the Landsat 8 OLI/TIRS image interpretation method, the Normalized Difference Vegetation Index (NDVI) algorithm, the Normalized Difference Built-up Index (NDBI) algorithm, and land surface temperature measurements using thermal bands 10 and 11 . The results showed that areas with high vegetation index had low temperatures while areas with low vegetation index had high temperatures. The effect of wetland area depends on land use conditions at the time of image recording and water bodies have no significant effect on LST.
\end{abstract}

Keywords Temperature, Vegetation, Built-Up Area, Urban Heat Island, Tropical Climate

\section{Introduction}

Several studies have indicated that there is a relationship between the availability of vegetation and the formation of urban heat islands. This can be seen in the research conducted by X. Zhang [1] which shows that the soil surface temperature is strongly influenced by socio-ecological variables such as vegetation index, built-up area index, water index, population density, and $\mathrm{CO}_{2}$ emissions of fossil fuels; cooling of the parking area is influenced by the selection of vegetation types by simulating a comparison of tree vegetation with grass [2].

According to X. D. Xiao [3], the cooling effect that occurs in the green (vegetated) area is strongly influenced by the condition of the green area, the green space average leaf area index (LAI), and the vegetation density index. While the cooling effect of each green area does not have a significant effect on the perimeter of the green area. Water bodies in green open spaces do not contribute to cooling, but the cooling effect is related to another climatic element, namely wind. From the perspective of urban green space planning and development, it is important to "increase the green area" and the green perimeter area ratio. In addition, suitable tree species must be selected in the replanting/reforestation process. The effect of urban reforestation in improving the quality of the urban environment/ecology can be largely determined by the type 
of plants, canopy density, and garden form. The loss of a large amount of Urban Green Space (UGS) during urbanization has a major influence on the urban thermal environment [4].

Vegetation height and canopy width have a major influence on land surface temperature. Maximum cooling in the area of Urban Heat Island (UHI) can be obtained at $93.33 \%$ vegetation cover and vegetation height of approximately $20 \mathrm{~m}$ [5]. Furthermore, enhancing and optimizing the single component of the garden structure in the form of a tree canopy can increase the cooling effect on the garden and the surrounding climate [6].

Another study explaining the effect of green infrastructure on climate change in Munich, Germany by comparing tree vegetation, green roofs, and green facades shows that locating vegetation strategically in heat-exposed areas is more effective than simply directing the percentage high green cover such as green roofs and green facades. Utilization of vegetation as a green facade that covers the building envelope can increase the mitigation effect on heat temperatures in the building and the surrounding area. This is an option, especially in areas where the addition is not an option due to the density of the building. In addition, green roofs can also be added as a multifunctional measure by providing additions such as a roof garden that serves to reduce water runoff, and maintain biodiversity [7]. In line with this, other studies have shown that the evaluation of the effect of shade on pedestrian comfort in urban areas is the dominant factor [8]. Urban trees serve as the most effective tool for urban heat island (UHI) mitigation including shaded areas and tree density. In addition, parks also have a very big role in reducing the temperature of $1-2^{\circ} \mathrm{C}$, and providing thermal comfort for residents in the vicinity [9], as well as the exact pattern of tree planting in the yard can lower the temperature to $2^{\circ} \mathrm{C}$ and humidity up to $4 \%$ increase [10].

Although several previous studies have discussed the effect of vegetation on the decline in UHI, however, studies that discuss the relationship of vegetation distribution covering the entire area of the city in a certain period have not been studied before Therefore, this study was carried out to analyze the effect of vegetation on the reduction of UHI and produce recommendations for the area of vegetated areas or green open spaces needed.

The purpose of this study are to analyze other factors that influence the formation of UHI and factors that influence in reducing UHI through the following stages: 1) Analyzing the effect of vegetation on the formation of UHI in a certain period; 2) Analyze the effect of vegetation density and distribution (green index) on UHI reduction.

\section{Materials and Methods}

\subsection{Study Area}

The research was carried out in Gorontalo City which is the capital city of Gorontalo Province. (Figure 1). The reason for choosing the location was because this area was the region with the fastest development growth in Gorontalo Province. This region has an archipelago tropical climate with a high surface temperature because it is in the equator. The geographical condition of Gorontalo City is in the Tomini Bay Area with the characteristics of physical land in the form of hills and coasts.

\subsection{Data Collection Method}

In this study, we used Landsat images acquired on July 31, 2021, and February 8, 2016 (Landsat 8 OLI/TIRS). Landsat 8 OLI/TIRs satellite image data used in this study consisted of a multispectral band consisting of bands 1-7 and band 9 with a spatial resolution of $30 \mathrm{~m}$. While the panchromatic band or band 8 has a resolution of $15 \mathrm{~m}$, and the thermal band (bands 10 and 11) has a resolution of $100 \mathrm{~m}$ but has been resampled up to $30 \mathrm{~m}$. The selection of image data is limited to cloud-free less than $10 \%$ which is to facilitate the image interpretation process.

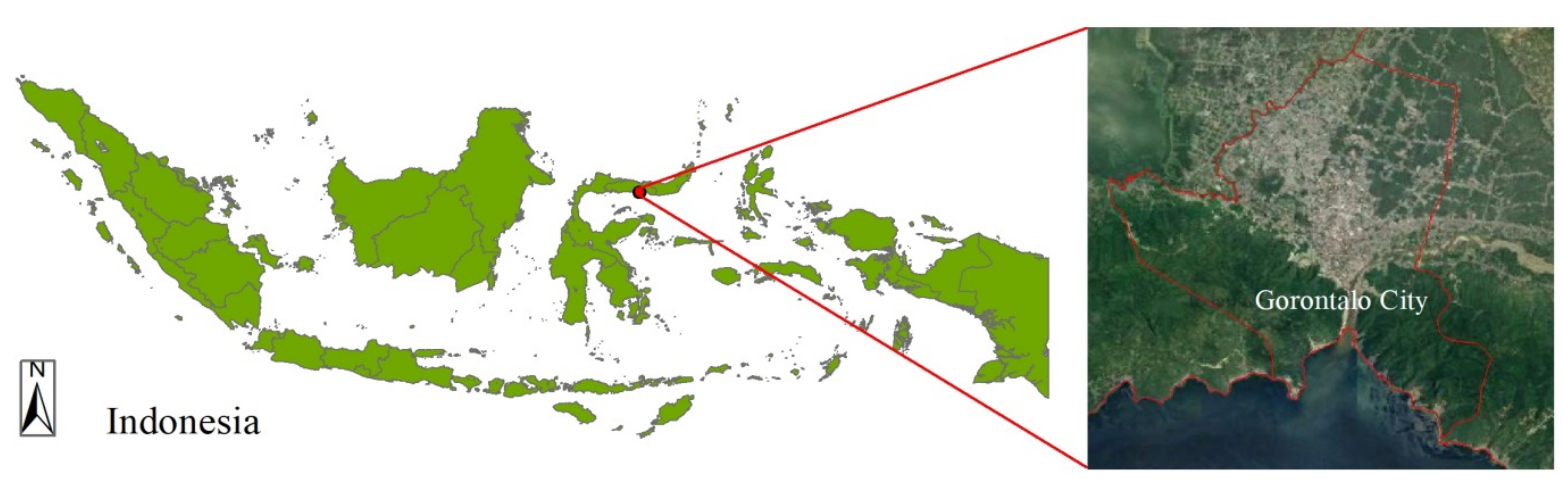

Figure 1. Study Area (Gorontalo City Map) 
The data used was downloaded from http://eartheexplorer.usgs.gov. (atmospheric correction C1L1) and all images have been geographically referenced to the WGS84/UTM projection system $51 \mathrm{~N}$ (coordinates of study site). This process has also changed the reflectance value from the multispectral band to the surface reflectance value and the thermal band which has been converted to the satellite brightness temperature expressed in Kelvin and further converted to degrees Celcius. Data processing for the calculation of the built area algorithm and vegetation index using band 4 (red), band 5 (Near Infrared), and band 6 (SWIR1).

The data collection method is through the interpretation of satellite imagery using ArcGIS 10.2. then perform ground checks at 20 locations to verify the data interpretation results. Processing data using algorithms on satellite imagery to calculate the area of surface temperature, index vegetation, and built-up area referring to previous studies [10]-[13].

\subsection{Data Analysis}

In this study, we use three stages of analysis, namely surface temperature analysis, green index analysis and built-up area analysis. The stages of the analysis are described as follows:

\subsubsection{Land Surface Temperatur (LST) Analysis}

Land Surface Temperature Measurement is carried out through the interpretation of Landsat TM8 images. Radiometric correction on Bands 10 and 11 Landsat 8 OLI / TIRS is carried out by changing the DN value to radiance by looking at information on the date, month, year of image recording, and sun elevation. After that, the spectral radiance to surface temperature $(\mathrm{K})$ calibration process was carried out using equation (1) to obtain the Kelvin temperature value (Landsat 8 Handbook).

$$
\mathrm{T}=\mathrm{K} 2 /(\operatorname{In}(\mathrm{K} 1 / \mathrm{L} \kappa+1))
$$

Where:

$\mathrm{T}=$ Kelvin Temperature $(\mathrm{K})$

$\mathrm{K} 2=$ spectral radian calibration constant $(\mathrm{W} /(\mathrm{m} 2 . \mathrm{sr} . \mu \mathrm{m})$, obtained from metadata

$\mathrm{K} 1=$ absolute temperature calibration constant $(\mathrm{K})$, obtained from image metadata

$\mathrm{L} \lambda=$ TOA spektral radiance

Referring to the method used by Ranagalage [14], the thermal band has been converted to the satellite brightness temperature which is expressed in Kelvin temperature units. Furthermore, the LST value can be obtained after determining the emissivity of the soil surface $(\varepsilon)$ first using Equation (2).

$$
\varepsilon=(\mathrm{m} \times \mathrm{PV})+\mathrm{n},
$$

where the values of $m=(\varepsilon)(1) F \varepsilon v$ and $n=s+(1 s) F \varepsilon v$, while $\mathrm{s}$ and $\mathrm{v}$ are soil emissivity and vegetation emissivity, respectively. The values used in this study are $m=0.004$ and $\mathrm{n}=0.986$.

$\mathrm{PV}$ is the estimated value of the vegetation cover fraction obtained from extraction using the NDVI algorithm equation (3).

$$
\mathrm{PV}=((\mathrm{NDVI}-\mathrm{NDVImin}) /(\mathrm{NDVImax}-\mathrm{NDVImin}))^{2},(3)
$$

where NDVI is the difference between the reclassification of the vegetation and soil indices derived in Equation (5) (see Section 2.3.2.). NDVImin and NDVImax are the minimum and maximum values obtained from the calculation process using the NDVI Algorithm.

Furthermore, the emissivity-corrected LST value is then calculated using Equation (4).

$$
\operatorname{LST}\left({ }^{\circ} \mathrm{C}\right)=\mathrm{TB} / 1+(\lambda \times \mathrm{TB} / \rho) \ln \varepsilon,
$$

where $\mathrm{TB}=$ spectral radiance value which has been converted to brightness temperature in Kelvin; $\lambda=$ wavelength of emitted radiation $(\lambda=10.8 \mathrm{~m}$ for Landsat TIRS Band 10 and $=12 \mathrm{~m}$ for Band 11$) ; \varepsilon=$ emissivity of land surface; $\rho=\mathrm{hc} / \sigma(1,438 \times 10-2 \mathrm{mK}) ; \sigma=$ Boltzmann's constant $(1.38 \times 1023 \mathrm{~J} / \mathrm{K}) ; \mathrm{h}=$ Planck's constant $(6.626 \times 1034 \mathrm{Js})$, and $\mathrm{c}=$ the speed of light $(2,998 \times 108 \mathrm{~m} / \mathrm{s})$. We then convert the obtained LST value from Kelvin $(\mathrm{K})$, to degrees Celsius $\left({ }^{\circ} \mathrm{C}\right)$.

\subsubsection{Vegetation Index}

The NDVI value describes the vegetation density with the lowest value of -1 and the highest index value of +1 . Positive values represent areas with sparse to wide vegetation and negative values represent unvegetated areas or bodies of water. Calculation of vegetation density using the NDVI algorithm can be seen in equation 5 .

$$
\text { NDVI }=(\text { NIR }- \text { RED }) /(N I R+R E D),
$$

where NIR $=$ the reflectance value of the Near Infrared band or band 5 with a wavelength of $0.85-0.88 \mathrm{~m}$ and $\mathrm{RED}=$ the reflectance value of the RED band on Landsat 8 OLI imagery which has a wavelength of $0.64-0.67 \mathrm{~m}$.

NDVI has a low of -1.0 and a high of 1.0. Clouds, water, and non-vegetable objects have NDVI values less than zero. The scores that represent vegetation are in the range of $0.1-0.7$. If the index value is higher than this value, it means that the vegetation cover is healthier and denser like primary forest (Lillesand \& Kiefer). The calculation of the vegetation index is used in several studies that focus on studies related to vegetation and surface temperature [14]-[17].

The index Normalized Difference Latent Heat Index (NDLI) was proposed by [12] which is an algorithm for calculating vegetation and humidity. The use of band 6 (SWIR) in Landsat OLI imagery makes it easier to detect and distinguish the water and vegetation features. The NDLI value can be obtained through equation (6).

$$
\mathrm{NDLI}=(\text { GREEN }-\mathrm{RED}) /(\text { GREEN }+ \text { RED }+ \text { SWIR1 }),(6)
$$

where GREEN = band 3 wavelengths $0.53-0.59 \mu \mathrm{m}$, RED $=$ band 4 wavelengths $0.64-0.67 \mu \mathrm{m})$ and SWIR1 = band 6 wavelengths $1.57-1.65 \mu \mathrm{m}$ (for Landsat OLI). 


\subsubsection{Built-up Area}

The use of the NDBI index is more focused on urban areas. Analysis using this index is very useful in the land use planning process. As in the calculation of the vegetation index, the use of mathematical formulas on spectral transformations with two or more bands is also carried out in the calculation of the built-up area. The NDBI calculation uses Bands 5 and 4 for Landsat TM, while in Landsat OLI/TIRS Bands 6 and Band 5.

The calculation of the built-up area index using the NDBI algorithm has been widely used in previous studies [11], [18]-[21]. The process of calculating this index is almost the same as the calculation of the vegetation density index using NDVI.

The NDBI index uses the difference and ratio of the mid-infrared (MIR/SWIR1) or (B6) and near-infrared (NIR) or (B5) bands to provide an overview of the built-up area and it is calculated using the following equation:

$$
\text { NDBI }=(\text { SWIR } 1-\mathrm{NIR}) /(\text { SWIR } 1+\mathrm{NIR}),
$$

where SWIR1 is the Shortwave Infrared Band or Band 6 on Landsat 8 OLI which has a wavelength of $1.57-1.65 \mathrm{~m}$. While NIR is the Near Infrared Band or Band 5 on Landsat 8 OLI which has a wavelength of $0.85-0.88 \mathrm{~m}$.

\section{Result}

\subsection{Condition of the Study Area}

\subsubsection{Climate Condition}

Based on data from the Meteorology and Geophysics Agency of Gorontalo Province, the average temperature in Gorontalo City throughout 2020 ranged from $26^{\circ} \mathrm{C}-28^{\circ} \mathrm{C}$ with a minimum temperature of around $23^{\circ} \mathrm{C}$ and a maximum of $33^{\circ} \mathrm{C}$; minimum humidity $61 \%$ and maximum humidity $95 \%$. The highest amount of rainfall occurs in July at $366 \mathrm{~mm}$ and the lowest in May at $48 \mathrm{~mm}$.

Measurements of temperature and humidity were carried out at the same time in different locations based on the type of urban spatial pattern. The results of temperature measurements show that the temperature range at the measurement location is $30^{\circ} \mathrm{C}-40^{\circ} \mathrm{C}$ and the humidity is 42 - 80 percent. Temperature data at various location points based on urban spatial patterns can be seen in table 1 .

Table 1. Land Surface Temperature in 2016 and 2021

\begin{tabular}{|c|c|c|}
\hline Measuring Point & $\begin{array}{c}\text { Temperature } \\
\left({ }^{\circ} \mathrm{C}\right)\end{array}$ & $\begin{array}{c}\text { Humidity } \\
(\mathbf{\%})\end{array}$ \\
\hline Street & 40.3 & 49 \\
\hline Housing area & 36.0 & 42 \\
\hline Field & 34.4 & 53 \\
\hline Coast & 35.0 & 49 \\
\hline Shopping complex & 33.4 & 58 \\
\hline Hills & 30.2 & 80 \\
\hline Green Open Space (City Park) & 30.8 & 72 \\
\hline Ricefield & 34.0 & 80 \\
\hline
\end{tabular}

The measurement results at the research location show that the highest surface temperature is in the road area, and the lowest surface temperature is in the hilly area. Low temperatures in hilly areas are accompanied by high humidity, which is around 80 percent (can be seen in the chart in figure 2.).

\section{Temperature and Humidity}

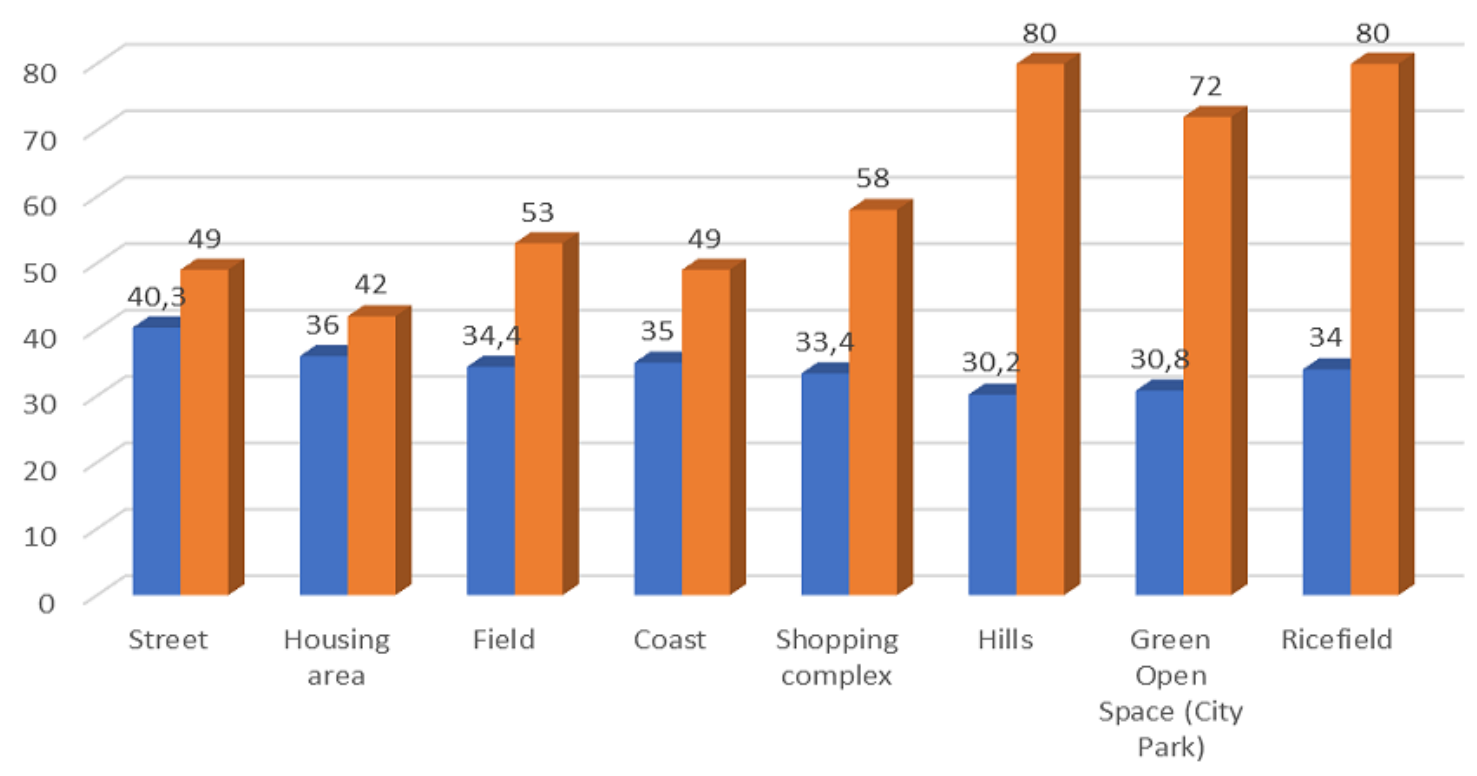

TEMPERATURE MUMADITY

Figure 2. Temperature and humidity chart based on land use in Gorontalo 


\section{TYPES OF SOIL IN GORONTALO CITY}

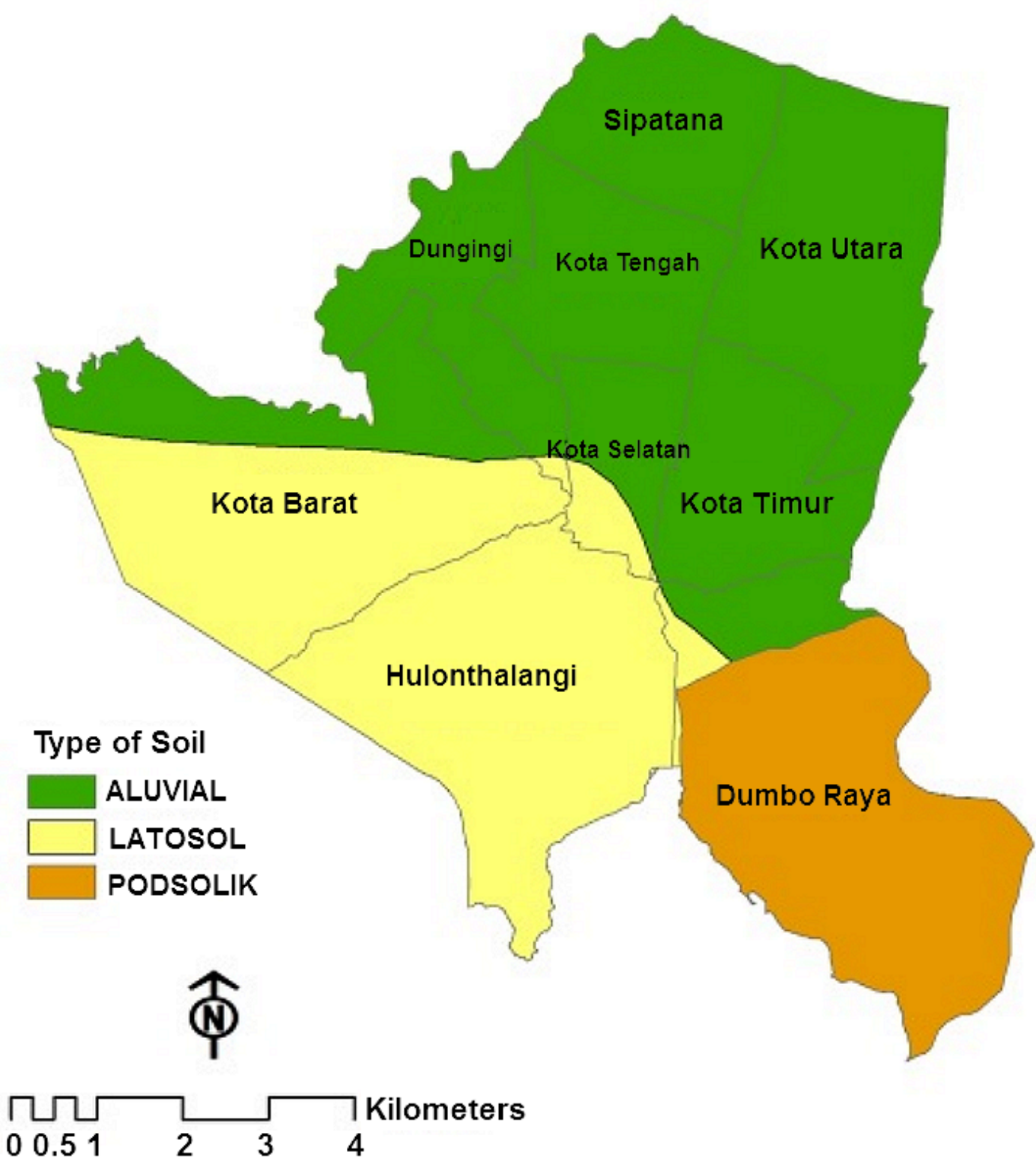

Figure 3. Map of Soil Type in Gorontalo City

\subsubsection{Soil Condition}

Soil types at the research site consisted of three types, namely: alluvial, latosol and podsolic. The alluvial soil type consists of 3,572.97 hectares of area, 2,288.67 hectares of latosol and 1,204.35 hectares of podsolic. The distribution of soil types in Gorontalo City can be seen in Figure 3.

\subsection{Land Surface Temperature}

The results of surface temperature analysis were obtained from the interpretation of Landsat TM8 satellite imagery recorded in 2015 and 2020. Surface temperature in the Gorontalo City area is classified into 4 classes, namely very low (less than $\left.21^{\circ} \mathrm{C}\right)$; low $\left(21-23^{\circ} \mathrm{C}\right)$; Medium $\left(23-25^{\circ} \mathrm{C}\right)$; High $\left(25-27^{\circ} \mathrm{C}\right)$ (Figure 4). 


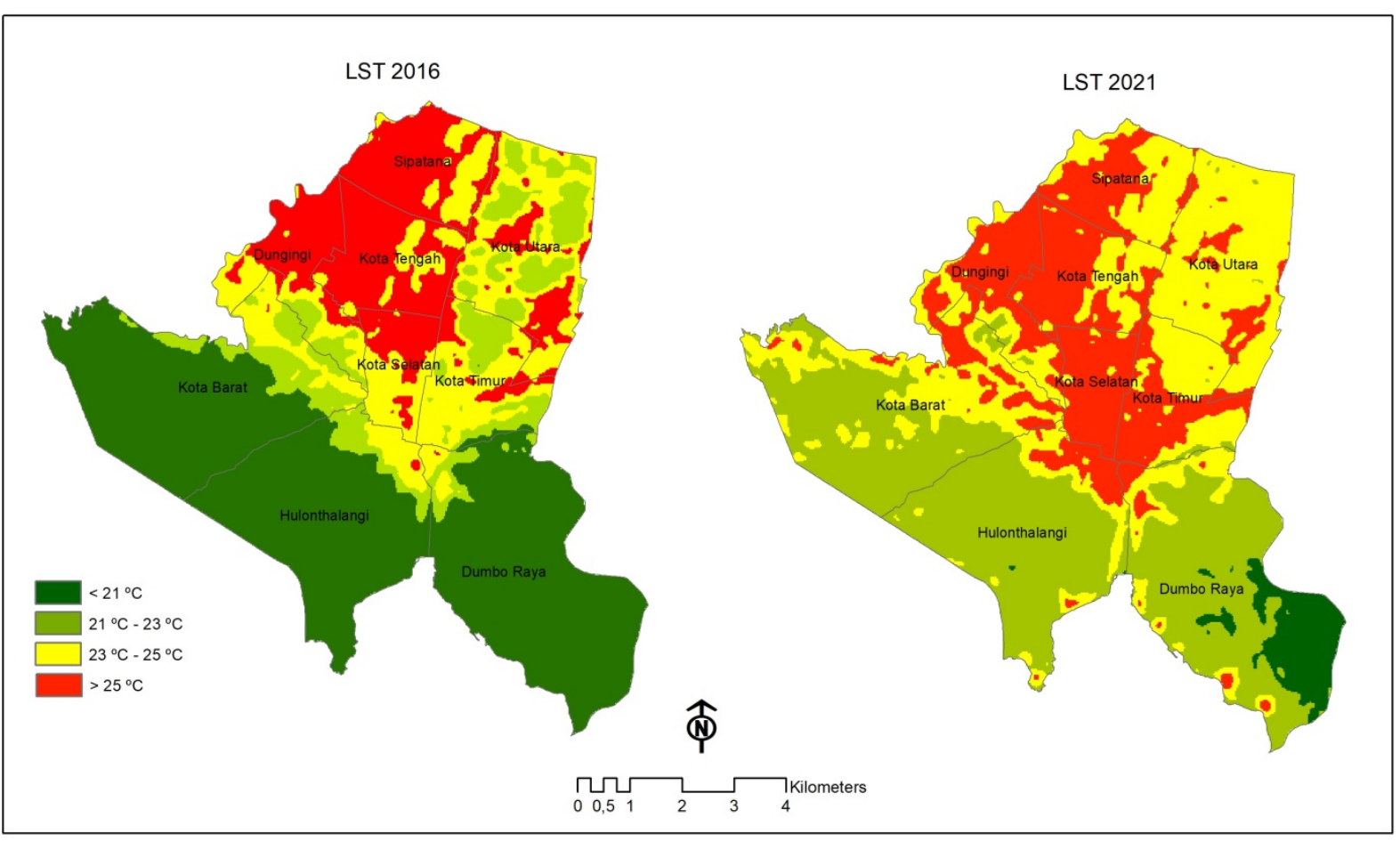

Figure 4. Land Surface Temperature (LST) maps of Gorontalo City area in 2016 and 2021

Table 2. Land Surface Temperature in 2016 and 2021

\begin{tabular}{|c|c|c|c|}
\hline LST Class & $\begin{array}{c}\text { Area } \\
\text { (hectare) }\end{array}$ & Percentage & Year \\
\hline$<21^{\circ} \mathrm{C}$ (very low) & $3,431.72$ & 48.57 & 2016 \\
$21^{\circ}-23^{\circ} \mathrm{C}$ (low) & 857.72 & 12.14 & \\
$23^{\circ}-25^{\circ} \mathrm{C}$ (moderate) & $1,392.86$ & 19.71 & \\
$>25^{\circ} \mathrm{C}$ (high) & $1,383.68$ & 19.58 & \\
\hline$<21^{\circ} \mathrm{C}$ (very low) & 304.49 & 4.31 & 2021 \\
$21^{\circ}-23^{\circ} \mathrm{C}$ (low) & $2,669.06$ & 37.77 & \\
$23^{\circ}-25^{\circ} \mathrm{C}$ (medium) & $2,307.26$ & 32.65 & \\
$>25^{\circ} \mathrm{C}$ (high) & $1,785.17$ & 25.26 & \\
\hline Total Study Area & $7,065.99$ & 100,00 & \\
\hline
\end{tabular}

Based on land surface temperature data obtained from 2 different times, namely 2016 and 2021, it shows that there is a change in the area of each LST class. The very low-temperature category covers the most extensive area in 2016 but in 2021 it will change to a low-class temperature, ranging from $21^{\circ} \mathrm{C}-23^{\circ} \mathrm{C}$. In addition, areas with high LST class show an increase in area in 2021. Data on changes in surface temperature can be seen in table 2.

\subsection{Vegetation Index}

NDVI serves to distinguish vegetation from other surface features. Bodies of water and non-vegetated areas are seen in darker colors and very low values. The results of the analysis using the Normalized Difference Vegetation Index (NDVI) algorithm show that the index value range is between -0.1 to 0.54 in 2016 and between -0.23 to 0.62 in 2021 . This shows that there is an increase in the vegetation index within 5 years in Gorontalo City.

In the NDVI index, a low value below zero can be interpreted as a body of water and a low positive value in the form of dry land or built-up areas, while vegetation is indicated by a high positive value. NDVI value more than 0.7 is primary forest [22]. 


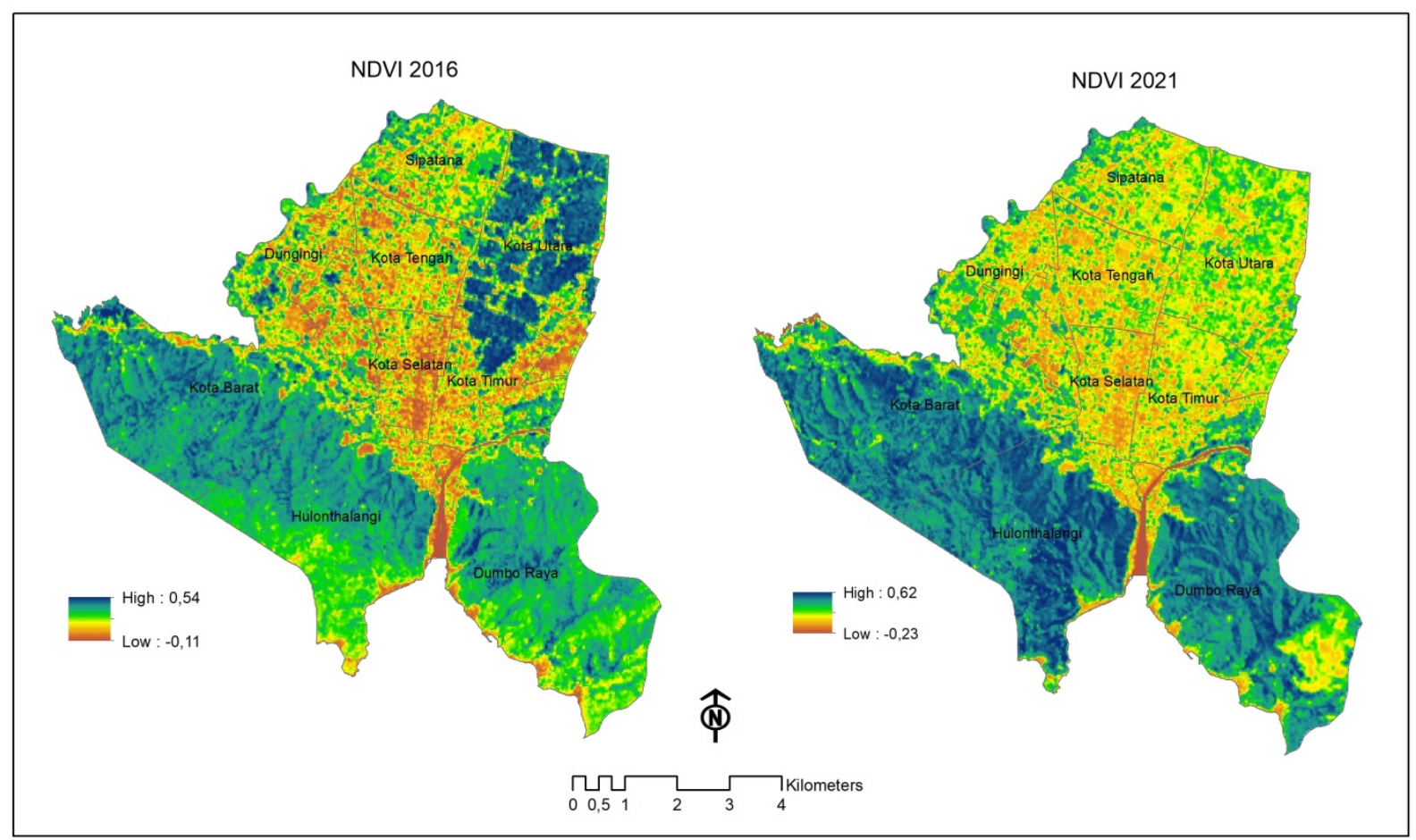

Figure 5. Vegetation index analysis results of the NDVI algorithm

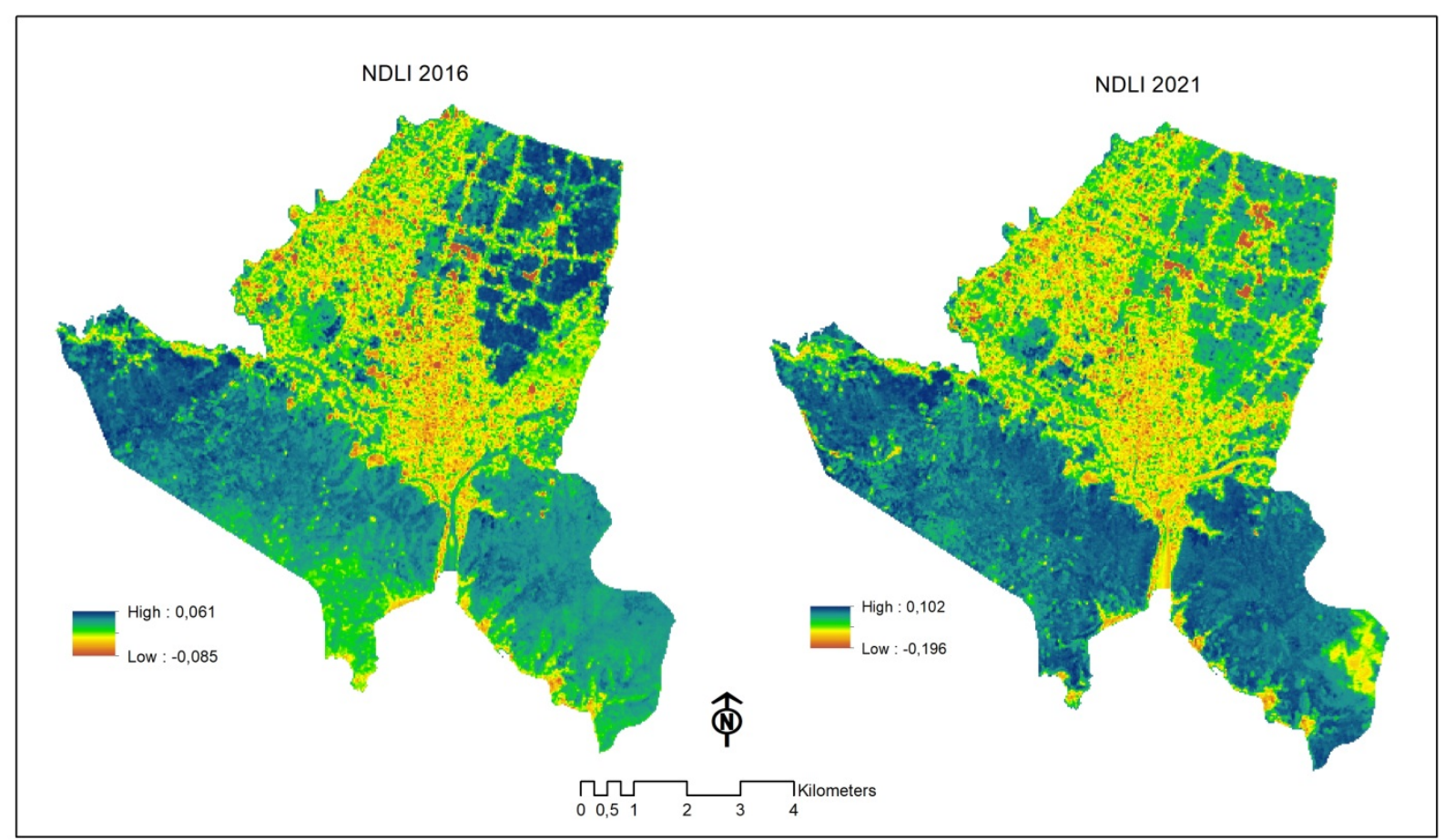

Figure 6. Vegetation index analysis results of the NDLI algorithm

In addition to using NDVI in calculating the vegetation index, this research also uses the NDLI algorithm (Figure 6.). The use of both NDVI and NDLI algorithms in the analysis of the vegetation index showed different results, but the distribution and density of vegetation did not show a significant difference.

The vegetation index using the NDVI and NDLI algorithms in 2021 (figures 5 and 6) shows differences in wetland agricultural areas (rice fields), where the NDVI analysis identifies vegetation into 2 classes, namely grass/shrub vegetation and tree vegetation. While the NDLI analysis of grass/shrub vegetation is divided into 2 parts which are wetlands (rice fields) with grass/shrubs on dry land. This can be seen in the image with a darker color. 
NDVI uses a band that is sensitive to chlorophyll produced by vegetation while NDLI detects vegetation and water (humidity) therefore areas that are wetlands (rice fields) can be identified. Unlike the case with NDVI, wetland areas are identified as surface vegetation (grass).

Negative values on the NDLI index represent dry land or built-up areas. A low positive value is vegetation and a high positive value is water feature combined with vegetation [12]. This explains that a high positive value is indicated by vegetation with high humidity, namely trees.

Table 3. Area and percentage of vegetation index based on NDVI value

\begin{tabular}{|c|c|c|c|}
\hline Vegetation Index & Area(hectare) & Percentage & Year \\
\hline Non vegetation & $1,505.85$ & 21,31 & 2016 \\
Sparse & $2,374.17$ & 33,60 & \\
vegetation (grass/shrub) & $3,185.97$ & 45,09 & \\
Dense vegetation (trees) & $1,973.61$ & 27.93 & 2021 \\
\hline Non vegetation & $1,611.90$ & 22,81 & \\
Sparse & $3,480.48$ & 49.26 & \\
vegetation (grass/shrub) & $7,065.99$ & 100,00 & \\
Dense vegetation (trees) & & & \\
\hline Total Study Area & &
\end{tabular}

The classification of the vegetation index is divided into 3 classes, namely non-vegetation, sparse vegetation (grass/shrubs), and dense vegetation (trees). The vegetated area based on the results of the analysis using the NDVI algorithm can be seen in table 3 .

Area data based on the 2016 and 2021 NDVI indexes show that there is an increase in the non-vegetation area by $6.62 \%$ within 5 years, a decrease in the area for the sparse vegetation index class by $10.79 \%$, and an increase in the area of dense vegetation $4,17 \%$.

\subsection{Built-up Area}

NDBI is an index that is used to calculate the built-up area index in urban areas. The calculation of the built-up area using the NDBI algorithm produces index values between -0.39 to 0.32 in 2016 and between -0.42 to 0.34 in 2021 (see figure 7). Based on the index value, it can be seen that the level of building density has increased over 5 years.

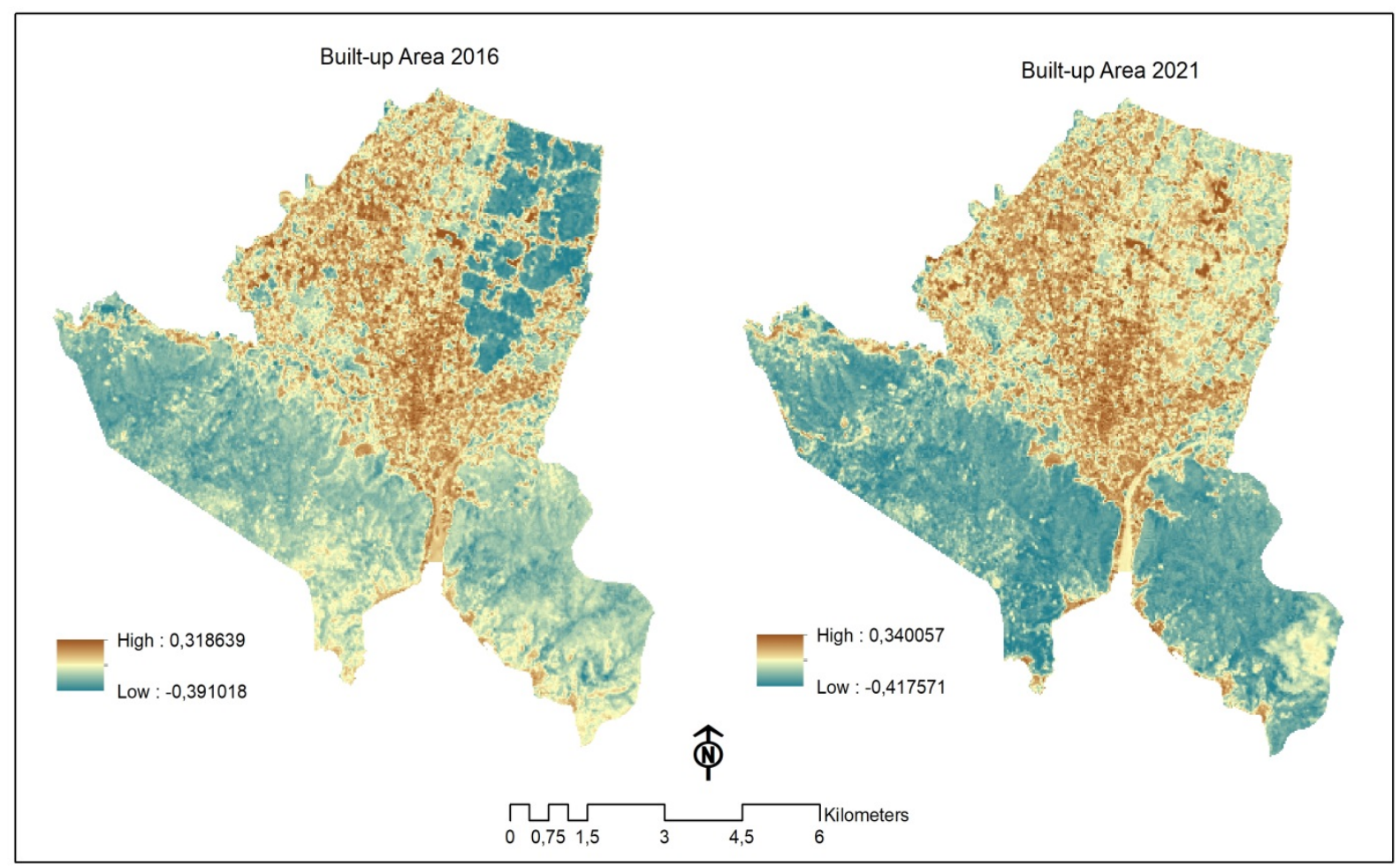

Figure 7. Built-up area in Gorontalo City 
The results of the analysis using NDBI are divided into 2 classifications, namely the built-up area and the non-built-up area. In general, built-up areas can be categorized into sparsely built-up areas and densely built-up areas, but in this case study, densely built-up areas were not found or present in very small quantities so that they were ignored. This is due to the lack of existing high-rise buildings in the study areas. Meanwhile, the unbuilt area consists of 3 typologies, namely vegetation, water bodies, and empty land. The area based on NDBI class can be seen in table 4 .

Table 4. Area and percentage of built-up area index based on NDBI value

\begin{tabular}{|c|c|c|c|}
\hline Ground Cover & $\begin{array}{c}\text { Area } \\
\text { (hectare) }\end{array}$ & Percentage & Year \\
\hline Non built-up area & $5,935.71$ & 84,00 & 2016 \\
Built-up area & $1,130.28$ & 16,00 & \\
\hline Non built-up area & $5,405.34$ & 76.50 & 2021 \\
Built-up area & $1,660.65$ & 23,50 & \\
\hline Total Study Area & $7,065.99$ & 100,00 & \\
\hline
\end{tabular}

Based on the built-up area index from 2016 to 2021, there was an increase in the built-up area in the study area by $7.51 \%$ or if averaged an increase in the built-up area by 1.5 percent every year.

\section{Discussion}

The result of a comparison between land surface temperature and vegetation index in 2021 shows that areas with high temperatures in the study area have a low vegetation index and areas with low temperatures have a high vegetation density index. The highest vegetation density is in the city area with conservation designation based on the planning document in the study area. The area is hilly and there is no built-up area in the area. This is in line with research conducted by [23] who found that there was a temperature difference of $2^{\circ} \mathrm{C}$ between vegetated and non-vegetated areas, so that a direct relationship was obtained between vegetated and non-vegetated areas, where lack of vegetation and formation of UHI [16].

In 2016, areas with low (cold) land surface temperatures will be in the same area in 2021 that is, in hilly areas and are not centers of activity in the city [24]. When compared with the vegetation index in the same year, it was found that locations with low surface temperatures were locations with high vegetation index, while locations with high surface temperatures had low vegetation index (less than 0.2). This is in line with [25] who found that properly planned tree planting was effective for reducing UHI during the day.

The increase in land surface temperature as shown by the results of the thermal band analysis of Landsat images resulted in the formation of urban heat islands. The UHI covers areas that have a low vegetation index and a high built-up area index. Therefore, it can be concluded that the main factors causing the formation of UHI in the study area are the lack of vegetation and the increase in the built-up area.

In the wetland agricultural area, the land surface temperature was in the low class in 2016, but in 2021 the temperature increased to medium. This is due to a decrease in the wet-land agricultural area accompanied by an increase in a built-up area which encourages changes in land use. Based on the urban spatial pattern, it can be seen that the highest vegetation index is found in protected areas whose land cover is dominated by tree vegetation. However, in 2021 there will be an increase in surface temperature in the area because during that time there has never been an attempt to increase the amount of vegetation through reforestation and other conservation activities. The increase in the amount of vegetation is not directly proportional to the increase in the built-up area. The availability of vegetation will greatly affect the increase in LST because a reduction in the amount of vegetation up to $51 \%$ results in an increase in LST of $23-43^{\circ} \mathrm{C} /$ year [26].

The type of soil at the research location also affects the type of vegetation that can grow at that location. Most areas have alluvial soil types which have high levels of nutrients and minerals so that they are very suitable for agriculture and are fertile soils for growing various types of vegetation. However, based on the distribution of the built-up area, the area with this alluvial soil type is mostly covered by buildings (solid coverage). While the podzolic soil type can store low nutrients, so this soil is less fertile. Based on the map of the distribution of soil types, this area is a hill located in the southeastern part of the research location. The area is slightly built-up with quite dense vegetation cover. Therefore, to develop the amount of vegetation in this area must be accompanied by proper selection of vegetation.

Areas with latosol soil types also have low-built areas with dense vegetation cover. The characteristics of latosol soil have medium to high nutrients, which are suitable for perennial types of plants or tree vegetation and are resistant to erosion. Therefore, this area has the potential for the development of green areas to increase the green index.

Climate has a very strong relationship with soil because climate such as temperature, rainfall and wind are factors that affect soil formation. On the other hand, land which is a growing medium for various vegetation and other biodiversity habitats will influence the climatic conditions around it. So this forms a mutually influential cycle [27].

\section{Conclusions}

This study analyzes the correlation between vegetation and the formation of urban heat islands (UHI). Based on 
the results of the analysis through the interpretation of Landsat 8 OLI/TIRS images, it is concluded that there is a relationship between high of land surface temperature (LST) and the availability of vegetation analyzed through the vegetation index. Areas with a high vegetation index have a low surface temperature while areas with a low vegetation index have a high surface temperature.

The results of the analysis were made by comparing the effect of vegetation on surface temperature in 2016 with 2021 showing the same results. Therefore, to plan for sustainable urban development, it is very important to prepare the availability of areas that have vegetation, especially trees, such as the availability of green open spaces.

\section{REFERENCES}

[1] X. Zhang, R. C. Estoque, and Y. Murayama, "An urban heat island study in Nanchang City, China based on land surface temperature and social-ecological variables," Sustain. Cities Soc., 2017, doi: 10.1016/j.scs.2017.05.005.

[2] A. Onishi, X. Cao, T. Ito, F. Shi, and H. Imura, "Evaluating the potential for urban heat-island mitigation by greening parking lots," Urban For. Urban Green., vol. 9, pp. 323332, 2010, doi: 10.1016/j.ufug.2010.06.002.

[3] X. D. Xiao, L. Dong, H. Yan, N. Yang, and Y. Xiong, "The influence of the spatial characteristics of urban green space on the urban heat island effect in Suzhou Industrial Park," Sustain. Cities Soc., vol. 40, no. April 2017, pp. 428-439, 2018, doi: 10.1016/j.scs.2018.04.002.

[4] Y. Cai, Y. Chen, and C. Tong, "Spatiotemporal evolution of urban green space and its impact on the urban thermal environment based on remote sensing data: A case study of Fuzhou City, China," Urban For. Urban Green., 2019, doi: 10.1016/j.ufug.2019.04.012.

[5] Q. Yu, M. Acheampong, R. Pu, S. M. Landry, and W. Ji, "Assessing effects of urban vegetation height on land surface temperature in," Int J Appl Earth Obs Geoinf., vol. 73, no. April, pp. 712-720, 2018.

[6] L. Mariani, S. G. Parisi, G. Cola, R. Lafortezza, G. Colangelo, and G. Sanesi, "Climatological analysis of the mitigating effect of vegetation on the urban heat island of Milan, Italy," Sci. Total Environ., vol. 570, pp. 762-773, 2016.

[7] T. Zölch, J. Maderspacher, C. Wamsler, and S. Pauleit, "Using green infrastructure for urban climate-proofing: An evaluation of heat mitigation measures at the micro-scale," Urban For. Urban Green., vol. 20, pp. 305-316, 2016.

[8] H. Saaroni, J. H. Amorim, J. A. Hiemstra, and D. Pearlmutter, "Urban Green Infrastructure as a tool for urban heat mitigation: Survey of research methodologies and findings across different climatic regions," Urban Clim., vol. 24, no. February, pp. 94-110, 2018, doi: 10.1016/j.uclim.2018.02.001

[9] F. Aram, E. Higueras, E. Solgi, and S. Mansournia, "Urban green space cooling effect in cities," Heliyon 5, vol. e01339, no. January, 2019, doi: 10.1016/j.heliyon.2019.e01339.

[10] J. Li et al., "The effect of tree-planting patterns on the microclimate within a courtyard," Sustain., vol. 11, no. 6, pp. 1-21, 2019, doi: 10.3390/su11061665.

[11] J. Chen, M. Li, Y. Liu, C. Shen, and W. Hu, "Extract residential areas automatically by new built-up index," 2010 18th Int. Conf. Geoinformatics, Geoinformatics 2010, no. 40701117, 2010, doi: 10.1109/GEOINFORMATICS.2 010.5567823 .

[12] Y. A. Liou, M. S. Le, and H. Chien, "Normalized Difference Latent Heat Index for Remote Sensing of Land Surface Energy Fluxes," IEEE Trans. Geosci. Remote Sens., vol. 57, no. 3, pp. 1423-1433, 2019, doi: 10.1109/TGRS.2018.2866555.

[13] Y. Zha, J. Gao, and S. Ni, "Use of normalized difference built-up index in automatically mapping urban areas from TM imagery," International Journal of Remote Sensing, vol. 24, no. 3. pp. 583-594, 2003, doi: 10.1080/014311603049 87.

[14] M. Ranagalage, R. C. Estoque, and Y. Murayama, "An urban heat island study of the Colombo Metropolitan Area, Sri Lanka, based on Landsat data (1997-2017), " ISPRS Int. J. Geo-Information, vol. 6, no. 7, 2017, doi: 10.3390/ijgi6070189.

[15] E. Margaritis and J. Kang, "Relationship between urban green spaces and other features of urban morphology with traffic noise distribution," Urban For. Urban Green., vol. 15, pp. 174-185, Jan. 2016, doi: 10.1016/J.UFUG.2015.12 .009 .

[16] I. P. Senanayake, W. D. D. P. Welivitiya, and P. M. Nadeeka, "Remote sensing based analysis of urban heat islands with vegetation cover in Colombo city, Sri Lanka using Landsat-7 ETM + data," vol. 5, pp. 19-35, 2013.

[17] Y. Jamei, P. Rajagopalan, and Q. Chayn, "Spatial structure of surface urban heat island and its relationship with vegetation and built-up areas in Melbourne, Australia," vol. 659, pp. 1335-1351, 2019.

[18] A. R. As-syakur, I. W. S. Adnyana, I. W. Arthana, and I. W. Nuarsa, "Enhanced built-UP and bareness index (EBBI) for mapping built-UP and bare land in an urban area," Remote Sensing, vol. 4, no. 10. pp. 2957-2970, 2012, doi: $10.3390 /$ rs4102957.

[19] S. Bouzekri, A. A. Lasbet, and A. Lachehab, "A New Spectral Index for Extraction of Built-Up Area Using Landsat-8 Data," Journal of the Indian Society of Remote Sensing, vol. 43, no. 4. pp. 867-873, 2015, doi: 10.1007/s12524-015-0460-6.

[20] Y. Zhou, G. Yang, S. Wang, L. Wang, F. Wang, and X. Liu, "A new index for mapping built-up and bare land areas from Landsat-8 OLI data," Remote Sensing Letters, vol. 5, no. 10. pp. 862-871, 2014, doi: 10.1080/2150704X.2014.9 73996.

[21] T. Susca, S. R. Gaf, and G. R. D. Osso, "Positive effects of vegetation: Urban heat island and green roofs," vol. 159, 2011, doi: 10.1016/j.envpol.2011.03.007.

[22] S. S. Arifin, Hamzah Baharuddin;, R. Mulyadi, and A. R. Rasyid, "Analysis Of Changes In Urban Heat Islands In Gorontalo City Using The Landsat TM8 Imagery," pp. 179-183, 2021. 
[23] L. E. N. Zheng Tan, Kevin Ka-Lun, "Urban tree design approaches for mitigating daytime urban heat island effects in a high-density urban environment," 2015, doi: 10.1016/j.enbuild.2015.06.031.

[24] S. Waseem and U. Khayyam, "Loss of vegetative over increased land surface temperature: A case study of Islamabad, Pakistan,” 2019.

[25] J. Frouz, "Soil biodiversity conservation for mitigating climate change," Clim. Chang. Soil Interact., pp. 1-19,
2020, doi: 10.1016/b978-0-12-818032-7.00001-1.

[26] H. Xu, "A new index for delineating built-up land features in satellite imagery," International Journal of Remote Sensing, vol. 29, no. 14. pp. 4269-4276, 2008, doi: 10.1080/01431160802039957.

[27] J. C. Thomas Lillesand, Ralph W. Kiefer, "Remote Sensing and Image Interpretation," in e-book, 7th Editio., WILEY, 2015. 